УДК 902.26

https://doi.org/10.24852/2587-6112.2020.5.62.68

\title{
РЕКОНСТРУКЦИЯ ПАЛЕОРЕЛЬЕФА И АРХЕОЛОГИЧЕСКОЕ ИЗУЧЕНИЕ ТЕРРИТОРИИ ИВАНЬКОВСКОГО И УГЛИЧСКОГО ВОДОХРАНИЛИЩ С ИСПОЛЬЗОВАНИЕМ ГИС-ТЕХНОЛОГИЙ
}

\author{
(C) 2020 г. В.О. Богданов
}

На основе сравнительного анализа картографических источников и с использованием ГИСтехнологий проведена реконструкция палеорельефа территории Верхнего Поволжья, подверженной техногенным изменениям. Работа по реконструкции палеорельефа Иваньковского и Угличского водохранилищ проведена путем восстановления водного рельефа до начала гидростроительства 30 -х годов XX века, при помощи программы QGIS 3.12 наложением слоев современной карты и «Карты Тверской губернии» А.И. Менде. Были получены варианты линии берегов р. Волга в изучаемом регионе, что позволило произвести картографирование археологических памятников. Уточнены данные о расположении известных и утраченных археологических памятников в данном регионе, отмечены их геоморфологические особенности.

Ключевые слова: археология Верхнего Поволжья, Иваньковское водохранилище, Угличское водохранилище, геоинформационные системы, палеорельеф.

\section{RECONSTRUCTION OF PALEORELIEF AND ARCHAEOLOGICAL STUDY OF IVANKOVO AND UGLICH RESERVOIRS USING GIS-TECHNOLOGIES}

\section{O. Bogdanov}

The palaeorelef of the territory of the Upper Volga region, which is subject to man-made changes, was reconstructed on the basis of a comparative analysis of cartographic sources and using GIS-technologies. The reconstruction of paleorelief in Ivankovo and Uglich reservoirs is carried out by restoring water terrain prior to the beginning of hydraulic engineering in the 1930s, using the QGIS 3.12 software by layering the modern maps and the "Map of the Tver province" by A. I. Mende. Options of the shoreline of the Volga river in the studied region were obtained, which made it possible to map the archaeological sites. The data on the location of known and lost archaeological monuments in the region were clarified, and their geomorphological features were noted.

Keywords: archaeology of the Upper Volga region, Ivankovsky reservoir, Uglichysky reservoir, geographic information systems, paleorelef.

Территория Верхнего Поволжья в долине реки Волги, а также прилегающие к ней надпойменные террасы с древности привлекали внимание охотников, рыболовов, собирателей, а позднее скотоводов и земледельцев. Благоприятный регион для расселения, он стал местом сосредоточения историко-культурных памятников и памятников археологии.

На всём протяжении Верхней Волги археологические памятники долгое время оставались в относительной сохранности. Впервые объекты культурного наследия Волжского бассейна подверглись крупномасштабному антропогенному воздействию в 1932-1937 гг. во время строительства канала «Москва - Волга» и особенно подготовки ложа Иваньковского и Угличского водохранилища. Большое количество деревень и крупный уездный город Корчева оказались в зоне затопления.
В 1932-1934 гг. в срочном порядке на строительных участках проводились археологические исследования. На территории будущего Иваньковского водохранилища работала экспедиция Государственной академии истории материальной культуры (ГАИМК) под руководством О.Н. Бадера, в её работе принимали участие научно-исследовательские коллективы из других регионов: учебно-исследовательский институт антропологии МГУ, Государственный Эрмитаж, Центральные государственные реставрационные мастерские, а также Дмитровский, Калининский и Кимрский музеи (Бадер, 1950, с. 8-14; Третьяков, 1935, с. 100-165).

В последующее время, в связи с формированием Угличского гидроузла, площадь археологических исследований значительно выросла. Были проведены масштабные спасательные археологические работы за короткий 
промежуток времени. В основном проводились разведывательные работы по выявлению неизвестных памятников, по авторской оценке Е.А. Бурдина было раскопано не более $10-15 \%$ от общего количества памятников археологии в зоне будущих водохранилищ (Бурдин, 2012, с. 9).

К сожалению, безвозвратно утраченные археологические памятники изучить полевыми методами не представляется возможным.

Восстановление облика древней земной поверхности, называемое палеогеоморфологической реконструкцией, является технически сложным и по результату не всегда однозначным. Также восстановление палеорельефа требует не только исторических методов, но и геолого-геоморфологических. Самое важное, что происходит эволюция форматов изображения: от картинных двухмерных изображений к объемным трехмерным и точным физико-географическим изображениям.

В данном исследовании на основе картографических источников и материалов полевых археологических работ с помощью геоинформационных технологий предпринята попытка реконструкции палеорельефа территории Иваньковского и Угличского водохранилищ.

В современной археологической науке применяют различные методы реконструкции палеорельефа, в большинстве случаев исследователи не ограничиваются первичным лабораторным анализом, а используют дополнительное оборудование. В качестве исходных материалов для восстановления палеорельефа на исследуемый период используются разномасштабные топографические и тематические картографические материалы, данные дистанционного зондирования (космические снимки), обработанные данные наземного лазерного сканирования отдельных поверхностей массива, данные геологических бурений, данные археологических раскопов и т. д. (Безвершенко, Данилов, Федоров, 2018, с. 3).

Работа по реконструкции палеорельефа Иваньковского и Угличского водохранилищ проведена на основе анализа данных картографических, дистанционного зондирования (космические снимки), археологических разведок и раскопок, не прибегая к помощи специалистов геологов. Пространственная привязка всех объектов проводилась в системе UTM для WGS84.

Наиболее важным было восстановление водного рельефа до начала гидростроительства 30-х годов XX века. Для этого при помо- щи программы QGIS 3.12 было сделано наложение слоев карты OSM Standart и «Карты Тверской губернии» А.И. Менде (Карта Менде, 1853). Последний картографический источник особенно информативен для выполнения поставленной задачи, так как позволяет определить местоположение всех географических объектов с наибольшей точностью (в сравнении с дистанционным зондированием). Карта включает, что также важно, регион будущих Иваньковского и Угличского водохранилищ и позволяет провести локализацию на этой территории археологических памятников, так как все они привязаны к местоположению населённых пунктов, имеющихся на карте.

После совмещения слоев и получения варианта линии берегов р. Волги в изучаемом регионе до 30-х гг. XX в. производилось картографирование археологических памятников относительно населенных пунктов, линии берега Волги и ее притоков. При этом самым точным ориентиром стали церкви, перекрёстки, улицы деревень, сохранившиеся до нашего времени. Данный вид ориентиров был подобран по критерию сохранности, так как важно, чтобы расположение объектов из старой карты находилось на современной карте без изменения фактического расположения. Сведения о локализации памятников были взяты из первой части издания «Археологическая карта России. Тверская область». Работы О.Н. Бадера «Археологические работы в зоне канала имени Москвы» и исследования П.Н. Третьякова «Работы на строительстве Ярославской гидроэлектростанции» дают информацию конкретно по затопленным памятникам (Археологическая карта России, 2003, с. 148-168; Бадер, 1950, с. 8-14; Третьяков, 1935, с. 100-165). Памятники были разделены по хронологическому принципу: мезолит, неолит, бронзовый век, ранний железный век, ранее Средневековье и позднее Средневековье. По каждому памятнику в ГИС включены следующие данные: наименование, тип, датировка, размеры, находки.

При выявлении местоположения памятников были выделены микрорегионы, где концентрируется наибольшее количество археологических памятников, полностью или частично утраченных в ходе гидростроительства. Данных регионов было выделено 3 (рис. 1, 2). В каждом из микрорегионов две растровые карты были наложены друг на друга, чтобы наглядно сравнить ландшафт, а 
также отмечены линии берега старые и актуальные.

В Сухаринском микрорегионе установлено расположение курганной группы до разрушения. Это мыс левого берега реки Волги и правый берег безымянного ручья, в 700 метрах к юго-западу от бывшей деревни Сухарино (ныне затопленной). Карта Менде по ориентирам (безымянная река, деревня, линия берега реки Волги) дает нам возможность локализации археологического памятника: это около 300 метров от линии берега. Также наложенная карта Менде хорошо показывает очертания разрушенной деревни, на современной карте это часть реки и острова (рис. 3 ).

Корчевской микрорегион по площади более других был подвержен антропогенным изменениям. Воздействие воды образовало на относительных возвышенностях острова, а на юге микрорегиона под воду ушел и сам уездный город Корчева. Как и в первом микрорегионе, есть возможность провести учет разрушенных археологических памятников, а также деревень, существовавших до 30 -х годов XX вв. При наложении слоев была восстановлена старая линия берега, на которой располагались археологические памятники. Здесь наблюдается их неравномерное расположение, что связано с недостаточной степенью обследования территории - так, на правом берегу реки Волги на протяжении более 40 км археологических памятников не выявлено (рис. 4).

Басовской микрорегион выделяется наибольшим числом затопленных археологических объектов - 12 памятников. На карте Менде приток реки Волги имеет «петли», на которых располагались селища и городища. Концентрация разновременных памятников в регионе свидетельствует о благоприятных условиях для расселения. Данный микрорегион показателен тем, что там, где были притоки реки Волги, вода распространилась в первую очередь с учетом высот береговой линии. Археологические памятники, особенно городища, располагаются на первых или вторых надпойменных террасах мысовых участков реки Волга и его притоков. Так, очертание притоков на карте Менде позволяют определить точное расположение памятников, а в последующем и локализовать их в пространстве актуальной карты (рис. 5, 6).

В итоге последовательной работы по картографии памятников в ГИС были включены 210 объектов. Стоянки палеолита - 2, стоянки мезолита - 38, стоянки неолита - 49, эпохи бронзы - 13, городища РЖВ - 16 , селища РЖВ - 26, курганные группы - 13, селища Древней Руси - 23, городища X-XIII вв. - 2, селища позднего Средневековья - 26, городища позднего Средневековья - 2. Затопленных объектов выявлено более 25 памятников. Из всех типов памятников следует отметить хорошую сохранность курганных групп, поскольку они располагаются в большинстве случаев на высоких берегах и часто в относительной дали от русла реки.

Менее всего пострадали памятники южной части Угличского водохранилища в Кимрском районе (рис. 2), так как ландшафт берега на всей протяжённости имеет значительные возвышенности, и при наложении древней и современной линии берега они почти повторяют контур друг друга. Другая ситуация в Иваньковском водохранилище (рис 1), где больше притоков Волги, заболоченных мест и низин, которые были затоплены при гидростроительстве. В Иваньковском водохранилище выделяются большие участки с отсутствием археологических памятников, причинами могут быть как неблагоприятные для освоения условия, так и то, что данные территории слабо изучены археологами.

Отметим в целом, что большинство памятников в рассматриваемом регионе из-за гидростроительства и затопления 30-х гг. XX века оказались практически неисследованными (работы проводились только на 15\% памятников).

Созданная ГИС археологических памятников с учетом палеорельефа территории Иваньковского и Угличского водохранилищ позволила реконструировать систему расположения археологических памятников вдоль уничтоженных берегов Волги, не привлекая геологов, материальных затрат, специального оборудования и полевых методов работы.

Данная методика способствует выявлению новых археологических памятников, так как при создании ГИС выделяется информация о частично затопленных памятниках (например, курганных группах). А это означает, что при реконструкции палеорельефа можно на кабинетном уровне сделать предположение о возможном месторасположении еще не выявленных памятников и спланировать их полевое обследование.

При выполнении совмещения картографических материалов разного времени в 
ГИС необходимо стремиться к уменьшению погрешности в локализации объектов (в нашем случае она достигала иногда 300 метров). Данная погрешность связана с разной степенью точности старых карт по сравнению со снимками из космоса. Но геоинформационные технологии способствую минимизации погрешности старых карт благодаря наложению растровых точек.
Полученные результаты с использованием ГИС-технологий позволяют учитывать большой комплекс уничтоженных археологических объектов в научных исследованиях системы расселения, культурного освоения и региональных особенностей населения данных территорий в древности и Средневековье. Следовательно, проведенный опыт имеет дальнейшие перспективы.

\section{ИСТОЧНИКИ И ЛИТЕРАТУРА}

Археологическая карта России. Тверская область. Часть 1 / Под ред. А.В. Кашкина. М.: ИА РАН, 2003. $484 \mathrm{c}$.

Бадер О.Н. Археологические работы в зоне канала имени Москвы // Материалы по археологии Верхнего Поволжья / МИА. №13. / Отв.ред. П.Н. Третьяков. М.: АН СССР, 1950. С. 8-14.

Безвершенко Л.С., Данилов В.А., Федоров А.В. Методика реконструкции палеорельефа Увекского массива в XIII веке с использованием ГИС-технологий // Современные проблемы территориального развития. 2018. №3. С. 1-11.

Бурдин Е.А. Судьба археологических памятников в зоне гидростроительства на Верхней Волге (1932-1937 гг.) // Вестник УлГТУ. 2012. №3(59). С. 9-11.

Карта Менде Тверской губернии. URL: http://www.etomesto.ru/map-tver_mende. (Дата обращения: 15.01.2020).

Третьяков П.Н. Работы на строительстве Ярославской гидроэлектростанции // Археологические работы Академии на новостройках 1932-1933 гг. Вып.1. / Известия ГАИМК Вып. 109. / Отв. ред. И. Мещанинов. М.-Л.; Соцэкгиз, 1935. С. 100-165.

\section{Информация об авторе:}

Богданов Владимир Олегович, Тверской государственный университет (г. Тверь, Россия); bogdanoff.vowa2011@yandex.ru

\section{REFERENCES}

Kashkin, A. V. (ed.). 2003. Arkheologicheskaia karta Rossii. Tverskaia oblast' (Archaeological Map of Russia: Tver Oblast). Moscow: Institute of Archaeology, Russian Academy of Sciences Publ., (in Russian).

Bader, O. N. 1950. In Tret'yakov, P. N. (ed.). Materialy po arkheologii Verkhnego Povolzh ya (Materials on the Archaeology of the Upper Volga Region) Series: Materialy i issledovaniia po arkheologii SSSR (Materials and Studies in Archaeology of the USSR) 13. Moscow: Academy of Sciences of the USSR Publ., 8-14 (in Russian).

Bezvershenko, L. S., Danilov, V. A., Fedorov, A. V. 2018. In Sovremennye problem territorial'nogo razvitiia (Contemporary Issues of Territorial Development) 3, 1-11 (in Russian).

Burdin E. A. 2014. In Vestnik Ul'yanovskogo Tekhnicheskogo Gosudarstvennogo universiteta. (Bulletin of the Ulyanovsk State Technical University) 59 (3), 9-11 (in Russian).

Karta Mende Tverskoi gubernii (Map of Tver Governorate by Mende). Available at: http://www.etomesto. ru/map-tver_mende. (accessed: 15.01.2020.)

Tret'yakov, P. N. 1935. In Meshchaninov, I. (ed.). Arkheologicheskie raboty Akademii na novostroikakh 1932-1933 gg. (Archaeological Activities of the Academy at New Construction sites in 1932-1933). Series: Izvestiia Gosudarstvennoi Akademii istorii material'noi kul'tury (Reports of the State Academy for the History of Material Culture) (1). Moscow-Leningrad: “Sotsekgiz” Publ., 100-165 (in Russian).

\section{About the Author:}

Bogdanov Vladimir O. Tver State University. Zhelyabov Str., 33 Tver, 170100, Russian Federation; bogdanoff.vowa2011@yandex.ru 


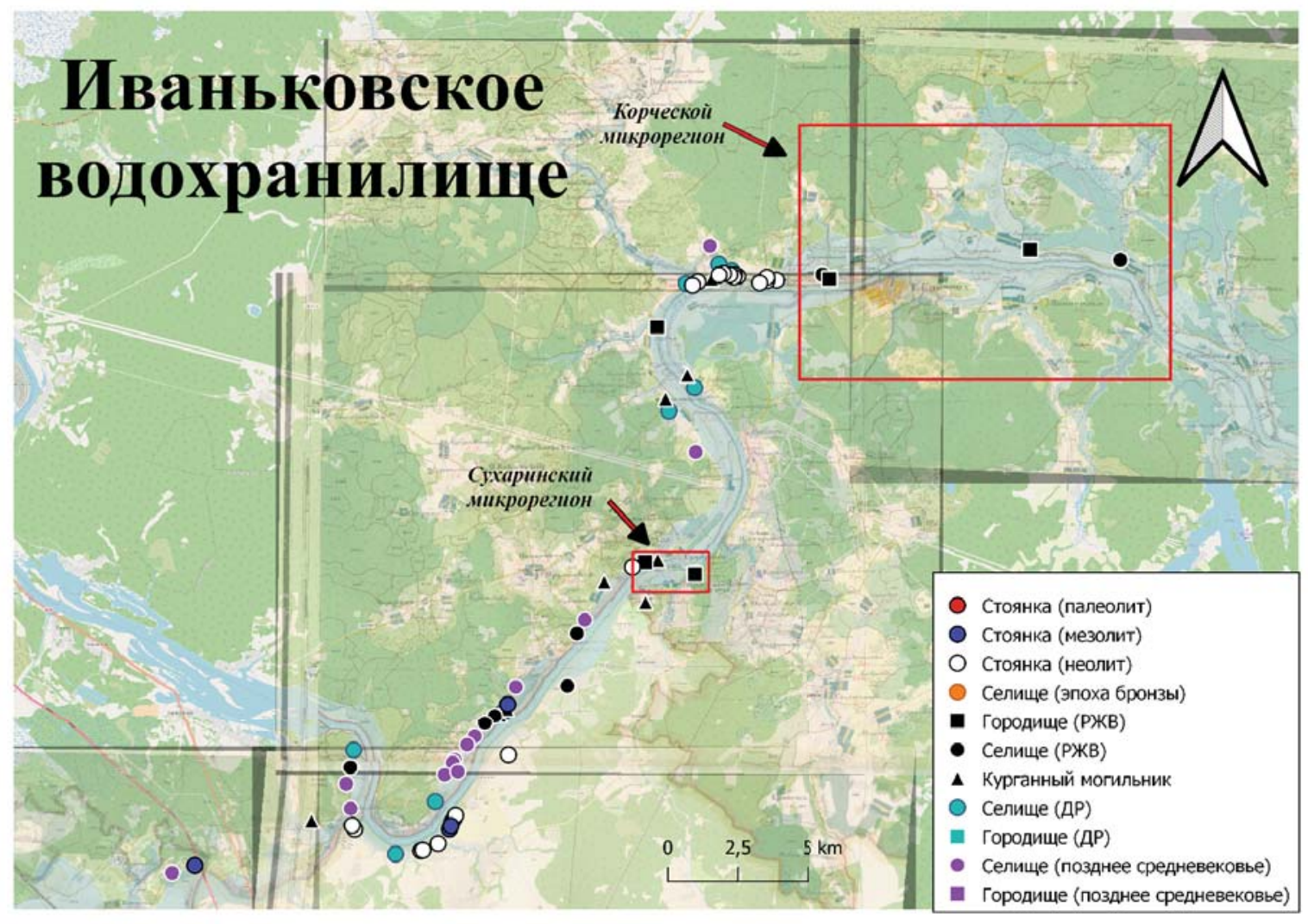

Рис. 1. Карта Иваньковского водохранилища с расположением археологических памятников. Fig 1. Map of Ivankovskoe Reservoir with the indication of archaeological sites.

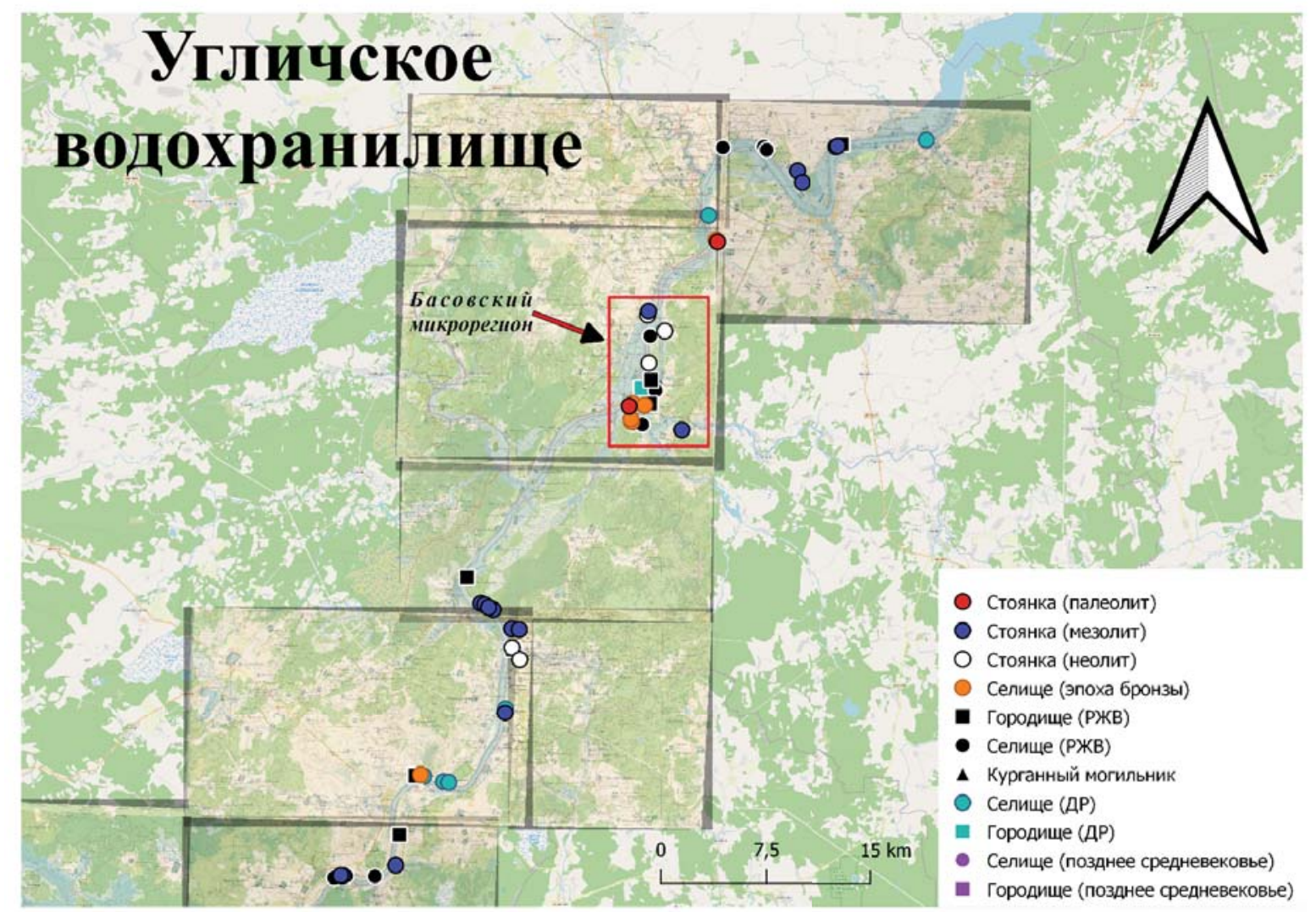

Рис. 2. Карта Угличского водохранилища с расположением археологических памятников.

Fig 2. Map of Uglich Reservoir with the indication of archaeological sites. 


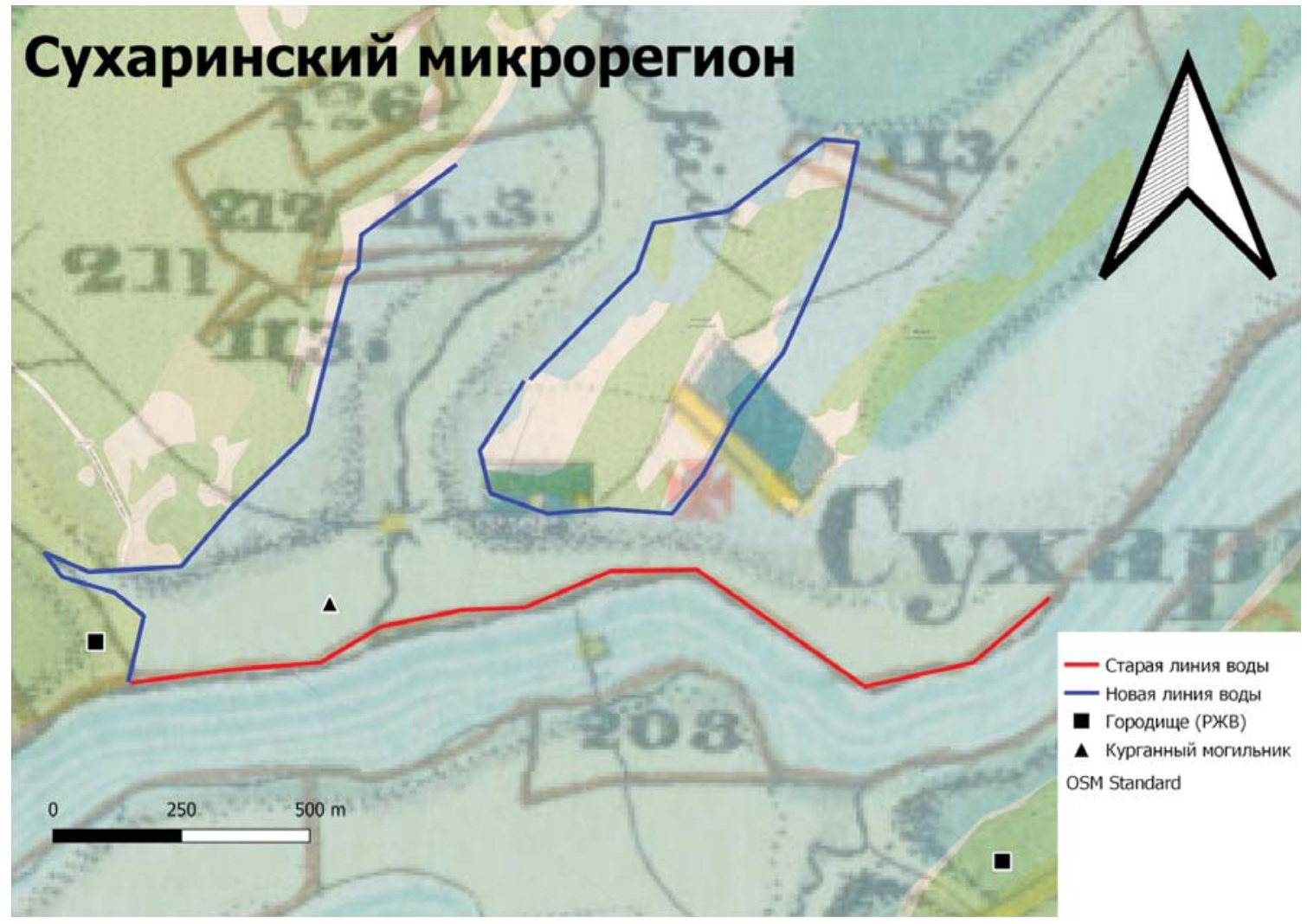

Рис. 3. Карта Сухаринский микрорегион с расположением археологических памятников и линий воды.

Fig. 3. Map of the Sukharinsky microregion with the indication of archaeological sites and water lines.

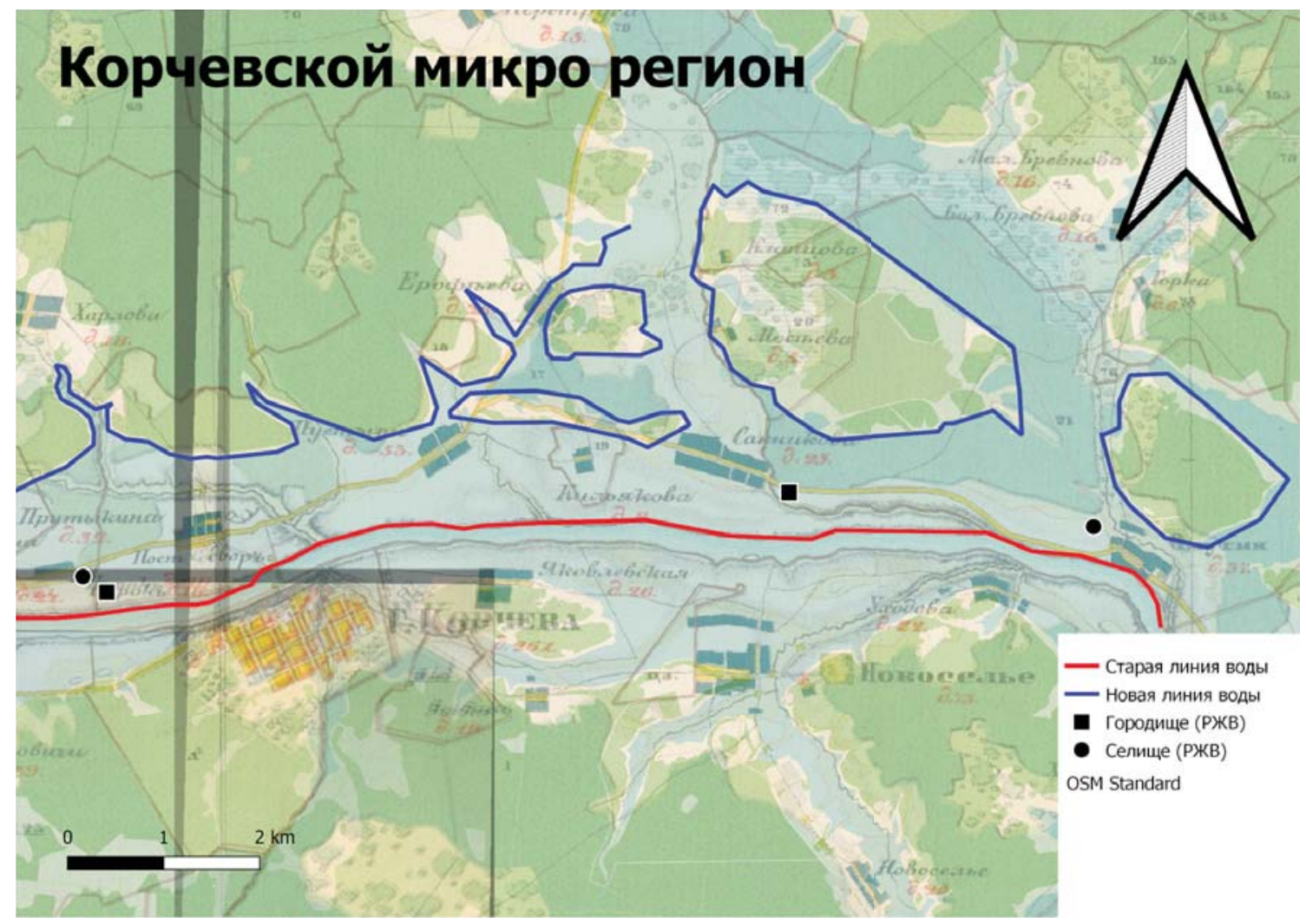

Рис. 4. Карта Корчевской микрорегион с расположением археологических памятников и линий воды.

Fig 4. Map of the Korchevsky microregion with the indication of archaeological sites and water lines. 


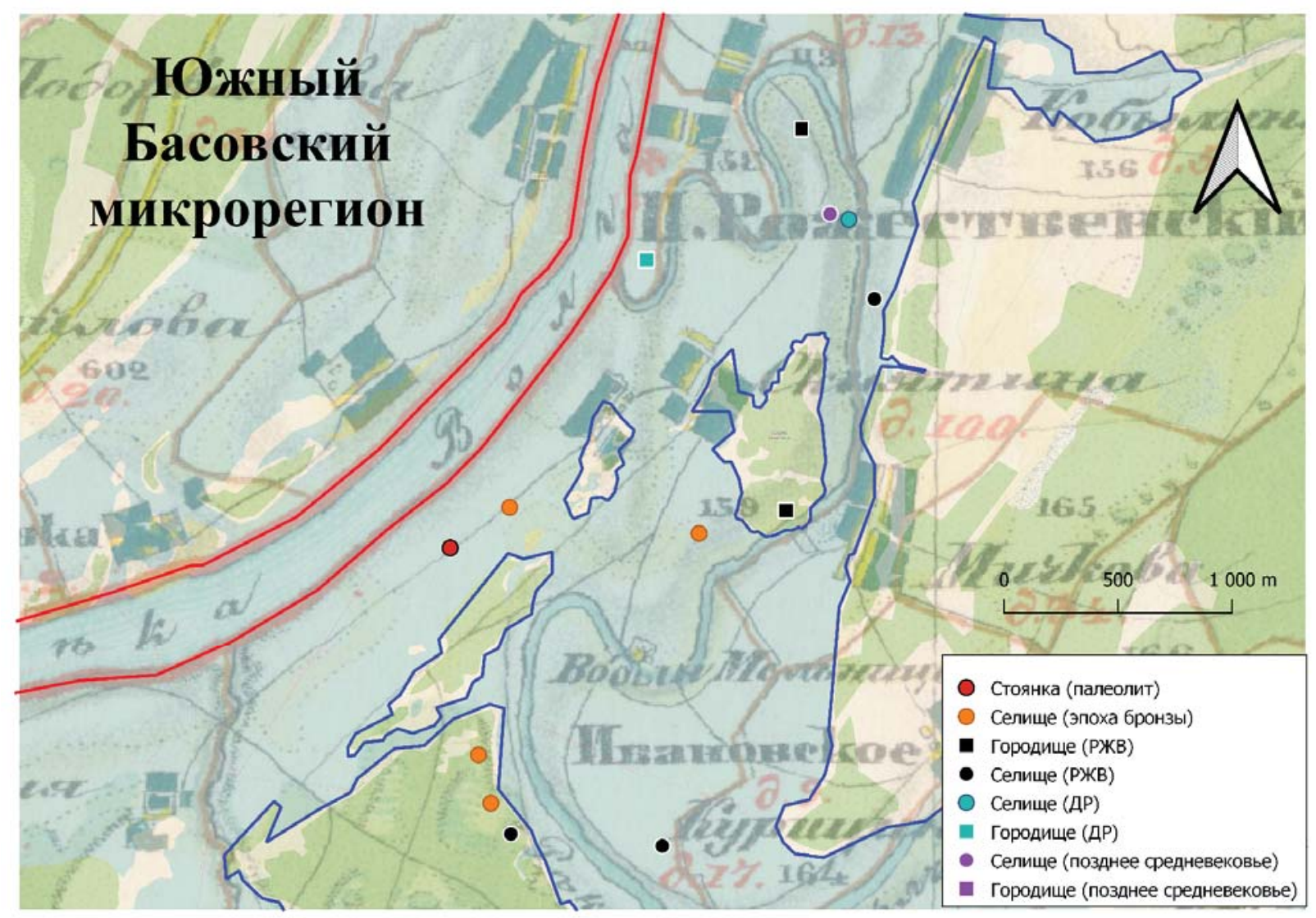

Рис. 5. Карта Басовского северного микрорегиона с расположением археологических памятников и линий воды. Fig 5. Map of the Basovsky northern microregion with the indication of archaeological sites and water lines.

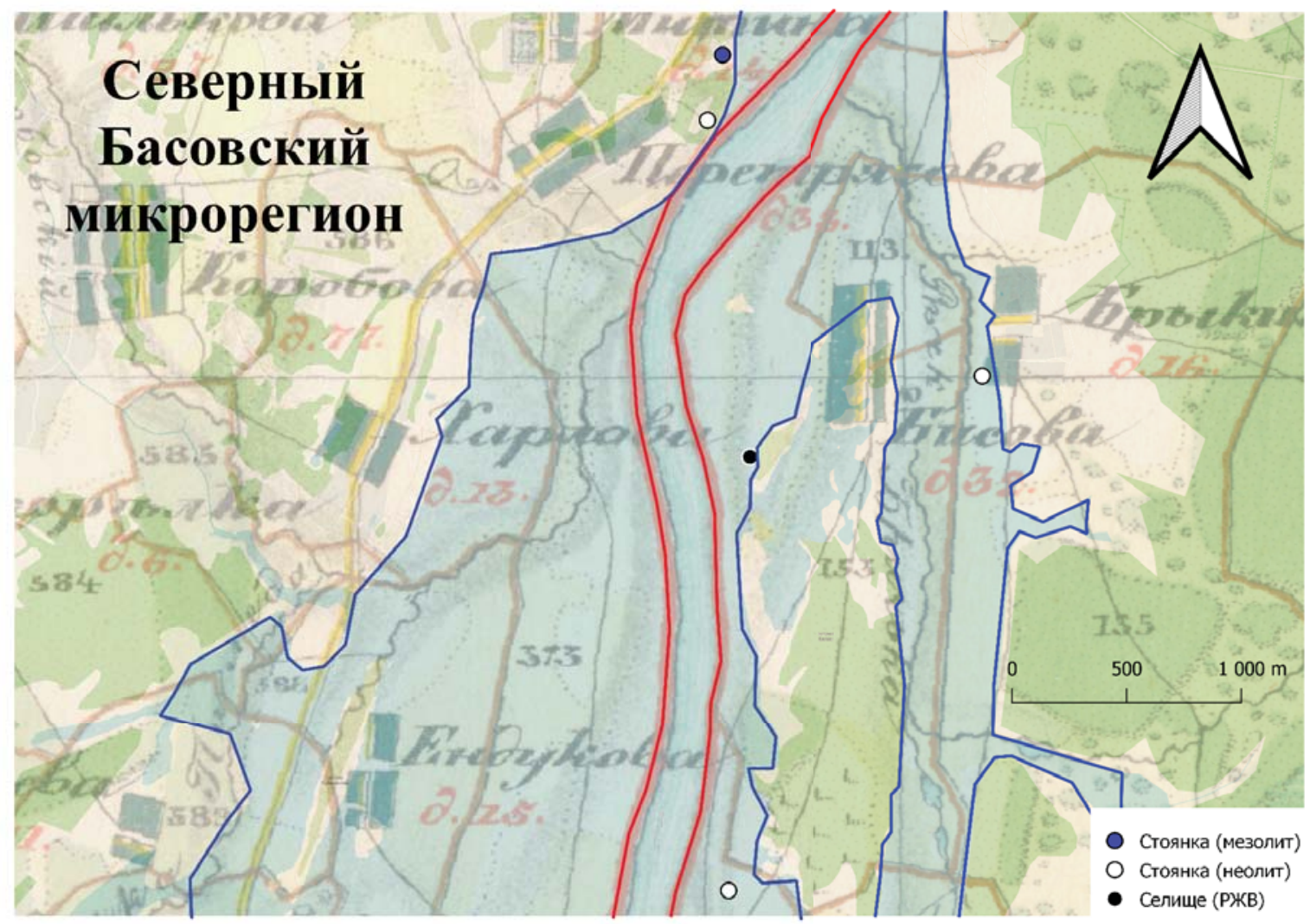

Рис. 6. Карта Басовского южного микрорегиона с расположением археологических памятников и линий воды. Fig 6. Map of the Basovsky southern microregion with the indication of archaeological sites and water lines. 